\title{
Correction to: Preventive Vertebroplasty for Long-Term Consolidation of Vertebral Metastases
}

\author{
Alexandre Delpla ${ }^{1,2} \cdot$ Lambros Tselikas $^{1,2} \cdot$ Thierry De Baere $^{1,2} \cdot$ Sophie Laurent $^{1,2} \cdot$ Karima $_{\text {Mezaib }}{ }^{1,2}$. \\ Maxime Barat $^{1,2}$ - Olivia Nguimbous ${ }^{1,2}$ - Clara Prudhomme $^{1,2} \cdot$ Marc Al Ahmar $^{1,2}$ Benjamin Moulin ${ }^{1,2}$. \\ Frederic Deschamps ${ }^{1,2}$
}

Published online: 4 March 2020

(C) Springer Science+Business Media, LLC, part of Springer Nature and the Cardiovascular and Interventional Radiological Society of Europe (CIRSE) 2020

Correction to: Cardiovasc Intervent Radiol (2019) 42:1726-1737 https://doi.org/10.1007/s00270-019-02314-6

In the original article, the following author name was incorrectly published and the corrected name is given below:
Incorrect author name: Marc Al-hamar.

Corrected author name: Marc Al Ahmar.

Publisher's Note Springer Nature remains neutral with regard to jurisdictional claims in published maps and institutional affiliations.
The original article can be found online at https://doi.org/10.1007/ s00270-019-02314-6.

Alexandre Delpla

adelpla@hotmail.fr

Lambros Tselikas

lambros.tselikas@gustaveroussy.fr

Thierry De Baere

thierry.debaere@gustaveroussy.fr

Sophie Laurent

sophie.laurent@gustaveroussy.fr

Karima Mezaib

karima.mezaib@gustaveroussy.fr

Maxime Barat

maxime.barat89@gmail.com

Olivia Nguimbous

olivia.nguimbous@gustaveroussy.fr

Clara Prudhomme

clara.prudhomme@gustaveroussy.fr

Marc Al Ahmar

marc.al-hamar@gustaveroussy.fr

Benjamin Moulin

b.moulin00@gmail.com

Frederic Deschamps

frederic.deschamps@gustaveroussy.fr
Interventional Radiology Unit, Imaging Department, Gustave Roussy Cancer Campus, 114 rue Edouard Vaillant, 94805 Villejuif, France

2 Paris-Sud, Le Kremlin Bicêtre, France 